\title{
Placar da Vida: o discurso de saúde pública por meio da divulgação de dados da Covid-19
}

\author{
Victória Sayuri Freire dos Santos KUDEKEN ${ }^{1}$
}

\begin{abstract}
Resumo:
O direito universal à saúde no Brasil surge a partir do Sistema Único de Saúde com a constituição de 1988. Os princípios organizativos são constituídos pela participação popular, a regionalização e a descentralização dos poderes federal, estadual e municipal, conferindo assim uma administração compartilhada e transparente com foco na equidade das práticas de saúde. Dessa forma, a apresentação dos dados epidemiológicos torna-se uma ferramenta para compreender os espaços e ações necessárias para o atendimento clínico e preventivo. O presente artigo tem como objetivo analisar algumas estratégias discursivas sobre a divulgação de dados do novo coronavírus a partir da publicação do "Placar da Vida" pelo Ministério da Saúde e as repercussões midiáticas e populares sobre as informações destacadas e omitidas no material de divulgação.
\end{abstract}

Palavras-chave: Saúde pública. Comunicação. Consumo simbólico.

\section{Placar da Vida: public health discourse through the dissemination of data from Covid-19}

\begin{abstract}
:
The universal right to health in Brazil arises from the Unified Health System with the constitution of 1988. The organizational principles are constituted by popular participation, regionalization and decentralization of federal, state and municipal government, a shared and transparent administration focusing on equity in health practices. The presentation of epidemiological data becomes a tool to understand the spaces and actions necessary for clinical and preventive care. This article aims to analyze some discursive strategies on the dissemination of data on the new coronavirus from the publication of the "Placar da Vida" by the Ministry of Health and the media and popular repercussions on the information highlighted and omitted in the dissemination material.
\end{abstract}

Keywords: Public health. Communication. Symbolic consume.

\section{Placar da vida: el discurso de salud pública a través de la difusión de datos de Covid-19}

\begin{abstract}
:
El derecho universal a la salud en Brasil surge del Sistema Único de Saúde con la constitución de 1988. Los principios organizativos están constituidos por la participación popular, la regionalización y descentralización de los poderes federal, estatal y municipal, com la intención de hacer una administración compartida, transparente y centrándose en la equidad de las prácticas de salud. Así, la presentación de datos epidemiológicos se convierte en una herramienta para comprender los espacios y acciones necesarias para la atención clínica y preventiva. Este artículo tiene como objetivo analizar algunas estrategias discursivas sobre la difusión de datos sobre el nuevo coronavirus a partir de la publicación del "Placar da Vida" por parte del Ministerio de Salud y los medios de comunicación y la repercusión popular sobre la información destacada y omitida en el material de diffusion
\end{abstract}

\footnotetext{
${ }^{1}$ Doutoranda em Comunicação e Consumo pela Escola Superior de Propaganda e Marketing (ESPM), bolsista PROSUP/CAPES. E-mail: vick-sayuri@hotmail.com
} 
Keywords: Salud pública. Comunicación. Consumo simbólico.

\section{Introdução}

As práticas de saúde e a experiência de consumo de ações, tratamentos e medicamentos para promoção, prevenção e cura têm em sua dinâmica o objetivo de completo bem-estar do indivíduo, não simplesmente erradicando doenças, mas também promovendo ações que se enquadrem nos diferentes modos de vida e das necessidades que compõem o atendimento clínico (VENTURA; SIMAS; PEPE; SCHRAMM, 2010). Na saúde pública, o cuidado individual e coletivo são compostos pela epidemiologia regionalizada, compreendendo as necessidades de cada espaço e quais as necessidades de asseguração da população frente à alimentação, às questões sanitárias de fábricas e estabelecimentos comerciais, controle e erradicação de doenças por meio de vacinas e o tratamento de quadros clínicos a partir das características etárias, sexuais, raciais e locais, fundamentadas pelo Pacto Internacional dos Direitos Econômicos, Sociais e Culturais (1976) ${ }^{2}$.

O direito universal à saúde sob o formato do Sistema Único de Saúde (SUS) teve sua legalidade a partir da Constituição de 1988, no qual se formalizou o acesso gratuito a tratamentos médicos, bem como meios de fiscalização, prevenção e promoção de saúde nos diferentes espectros em que as medicinas sanitarista e epidemiológica podem atuar na sociedade. O SUS tem como princípios três elementos que garantem o direito a saúde e uma visão calcada pela humanização e atuação em todo o território nacional, sendo estes a universalidade, a integralidade e equidade (BRASIL, 2000) ${ }^{3}$.

Para garantia dos princípios, as diretrizes organizacionais elencadas na legislação do SUS conferem a participação popular, a regionalização e a descentralização dos poderes federal, estadual e municipal com a participação de entidades públicas e privadas no planejamento e execução de ações em saúde. Na divisão de tarefas e competências promovidas pelos poderes, cabe ao Ministério da Saúde-MS a "divulgação de informações e análises epidemiológicas" e a "coordenação e execução das atividades de informação, educação e comunicação-IEC, de abrangência nacional" (BRASIL, 2003, p. 205).

\footnotetext{
${ }^{2}$ O Pacto Internacional dos Direitos Econômicos, Sociais e Culturais, organizado em 1966 pela Organização das Nações Unidas, com o intuito de promover o respeito universal e direitos de liberdade a partir de condições obrigatórias que possibilitem direitos econômicos, sociais e culturais (PACTO..., 1976).

${ }^{3} \mathrm{O}$ princípio de Universalidade define o direito o acesso de serviços de saúde a todas as pessoas em território nacional. Já a Equidade responde a demanda de diminuir desigualdades e compreender o atendimento a partir das necessidades individuais, visualizando também as questões socioeconômicas e dos ambientes de habitação e circulação. Por fim, a Integralidade promove um atendimento de saúde de forma interseccional, garantindo que todas as necessidades sejam desde a promoção, prevenção, tratamento e reabilitação dos indivíduos com o apoio de outros ministérios (BRASIL, 2000, p. 30-32).
} 
A divulgação dos dados epidemiológicos e seu uso, seja pelos poderes administrativos, pelas entidades públicas e privadas que participam dos planejamentos e ações de saúde ou pela população em sua participação no SUS, objetiva a transparência para uma forma cidadã nas tomadas de decisão. Ao refletir sobre as formas em que a divulgação pode ser realizada, é importante retomar os conceitos de Beer (2019) quanto ao uso de dados como forma de controle social e da manipulação algorítmica a partir de curadoria, manipulação, customização e direcionamento seletivo que interpelam os sujeitos que interagem a partir da intencionalidade em que as mensagens são divulgadas.

Para Foucault $(2015$, p. 144), a medicina moderna tem papel estratégico para o funcionamento do biopoder, ${ }^{4}$ uma vez que é pelo controle biológico do corpo que se inicia o controle da sociedade, não operando "simplesmente pela consciência ou pela ideologia". Ao pensar na comunicação dos dados e no consumo simbólico da saúde pública, sob as características dadas por Beer (2019) e da medicina como ferramenta biopolítica, é necessário compreender como são engendrados os discursos e as materialidades nas publicações.

No contexto de pandemia, como o caso da Covid-19 - uma doença causada pelo vírus Sars-CoV-2 e caracterizada por uma síndrome respiratória aguda - a união administrativa e de execução das práticas de saúde entre os poderes e a população reforça as responsabilidades conferidas pela legislação do SUS. Como processo estratégico, a informação dos dados regionais e o detalhamento de grupos de riscos por características de cada paciente e de indivíduos mais vulneráveis pelas condições socioeconômicas tornam-se necessários para a criação de protocolos e distribuição adequada de equipamentos e materiais de prevenção e tratamento na garantia de saúde da população.

A partir das comunicações de dados da Covid-19 veiculadas pelo MS como "Placar da Vida”, o presente artigo pretende responder à seguinte questão-problema: quais os lugares de disputa no consumo simbólico da saúde por meio da divulgação de dados do novo coronavírus? Como procedimento metodológico, será realizada uma breve discussão sobre o consumo simbólico da saúde pública e seus desdobramentos para os dados epidemiológicos. Em seguida, serão apresentados como são materializados os discursos de saúde a partir da perspectiva do MS pelo material "Placar da Vida" e as respostas de algumas instituições de comunicação e associações de saúde. Por fim, o material analisado será discutido pelas suas

\footnotetext{
${ }^{4}$ Veiga-Neto (2007), afirma que o biopoder, a partir dos estudos de Foucault, destina-se ao controle biológico da espécie, visando assim o controle da população e dos espaços ocupados pelo coletivo, normatizando condutas sociais e promovendo ações para um "bem comum".
} 
possibilidades de ação e emancipação a partir da atuação do jornalismo como instância avaliadora das políticas de saúde e as ações preventivas no consumo simbólico de saúde.

\section{O consumo simbólico da saúde pública e a política de divulgação de dados}

A saúde como uma demanda populacional e regulatória surge a partir da medicina social no século XVIII. Compreendendo questões como salubridade, controle epidemiológico e manutenção dos corpos para uma forma de trabalho, as práticas de saúde se desenvolveram com a normalização da profissão médica que, utilizada como uma estratégia biopolítica, ${ }^{5}$ regulariza as formas de vida, da organização das cidades e dos lugares de circulação (FOUCAULT, 2015).

A partir do Pacto Internacional dos Direitos Econômicos, Sociais e Culturais (1976), a saúde se torna uma responsabilidade mundial de ordem pública, no qual os cuidados individual e coletivo são compostos pela epidemiologia regionalizada, compreendendo as necessidades de cada espaço e quais as necessidades de asseguração da população frente à alimentação, às questões sanitárias de fábricas e estabelecimentos comerciais, controle e erradicação de doenças por meio de vacinas e o tratamento de quadros clínicos a partir das características etárias, sexuais, raciais e locais. Como ponto de partida para que cada governo repense em suas formas de ofertar estruturas salubres para suas regiões, a saúde ocupa um lugar de destaque para estabelecer modos de vida visualizados como dignos e básicos socialmente.

Se as condutas e modos de vida são indicados por meio dos saberes médicos para uma forma saudável de habitar o espaço social, os insumos e aparatos que surgem para manutenção salubre dos espaços e corpos constroem um engendramento simbólico dos usos e do próprio consumo em saúde.

O consumo, visto além do utilitarismo, se estabelece a partir de critérios sociais e sua função essencial é sua capacidade de dar sentido, compreendendo a construção cognitiva dos bens e suas relações sociais (DOUGLAS; ISHERWOOD, 2004). No caso da saúde, o consumo se estabelece nos processos de prevenção, promoção e tratamento, em situações como a alimentação focada em um determinado estilo de corpo, a higiene pessoal e de

\footnotetext{
${ }^{5}$ Afirmação de Foucault, quando a origem da Medicina Social é percebida pela influência da profissão médica na normatização dos corpos para um funcionamento adequado às necessidades do Estado. "O controle da sociedade sobre os indivíduos não se opera simplesmente pela consciência ou pela ideologia, mas começa no corpo, com o corpo. Foi no biológico, no somático, no corporal que, antes de tudo, investiu a sociedade capitalista. O corpo é uma realidade biopolítica. A medicina é uma estratégia biopolítica" (FOUCAULT, 2015, p. 144).
} 
ambientes para o alcance de prevenção de possíveis doenças e, da forma mais visível, a ingestão de medicamentos para o tratamento de algum problema diagnosticado. Ao entrar no circuito da mercadoria, não de forma estável ou por todo o tempo, a saúde obedece a padrões e critérios que promovem sua trocabilidade a partir dos contextos sociais.

Ao afirmar que "o consumo começa onde termina o mercado", Douglas e Isherwood (2004, p. 101), ampliam uma visão do consumo para além de algo utilitarista, reforçando que "a função essencial do consumo é sua capacidade de dar sentido" (DOUGLAS; ISHERWOOD, 2004, p.108). A esta construção cognitiva dos bens, é importante compreender como a materialidade dos insumos tornam-se a parte visível da cultura e como suas estruturas estão inseridas nos propósitos e significados estabelecidos socialmente. Para que esse processo ocorra, outro elemento necessário é a interação humana, uma vez que:

[...] os bens de consumo definitivamente não são meras mensagens, eles constituem o próprio sistema. Tire-os da interação humana e você desmantela tudo. Ao serem oferecidos, aceitos ou rejeitados, eles reforçam ou solapam as fronteiras existentes (DOUGLAS; ISHERWOOD, 2004, p. 120).

Ao assimilar o consumo de bens - a partir de sua visibilidade cultural e entrada nos propósitos sociais - o aceite ou não desses bens depende da interação humana e de como tais insumos serão utilizados, organizados e desprezados, a partir do momento em que tornam-se obsoletos. Como parte dos significados estabelecidos socialmente, é relevante pensar também como o consumo se articula a partir de visibilidades que interagem com os estilos de vida, com as rotinas e necessidades individuais que, pelos insumos exibidos e consumidos, partilham de uma forma reconhecível a ser vista pelas significações dadas pelos bens em uso.

Ao relacionar a concepção de consumo com a saúde, o que se pode ver é seu caráter simbólico para determinação de práticas e rituais que correspondem aos critérios sociais vigentes em relação ao cuidado do corpo. Segue-se as normas pela necessidade de alcançar determinado estado de saúde a partir de uma terapêutica, seja ela em um processo de promoção, prevenção ou de cura, onde sua materialidade está na forma de uma rotina de práticas saudáveis, o atendimento clínico para manutenção do corpo, o tratamento de doenças, uso de medicamentos e o retorno à "normalidade" desejada por essa visão de saúde.

Compreendendo o consumo simbólico como uma lógica que permeia culturas nas escolhas e aquisições dos bens, refletindo nas características sociais e econômicas dos 
indivíduos para a construção de um "status social” (WILLEMS, 2013), a saúde pode ser visualizada pelo consumo simbólico por um imaginário do que é qualidade e bem-estar nas práticas clínicas, adquirindo materialidades contrastantes uma vez que os serviços de saúde privados e públicos possuem recursos distintos para o atendimento. No caso do SUS como um promotor de bens simbólicos de consumo, as práticas de promoção e prevenção em saúde ganham complexidade não somente na estrutura e materialização dos atendimentos como também pelos imaginários do que é um atendimento de qualidade e como pode funcionar a dinâmica de participação das instituições, órgãos administrativos e população nas condutas de planejamento do sistema de saúde.

A partilha de dados gerais e detalhados do SUS é uma ferramenta de auxílio na construção de práticas de saúde, não somente em sua administração na esfera dos poderes governamentais responsáveis, como também um guia para projetos de promoção e prevenção de saúde. Dessa maneira, a população é visualizada como sujeito ativo nas condutas e na eficácia das indicações especializadas. Nesse sentido, o consumo simbólico do SUS a partir de sua prevenção acontece pela interferência das informações e indicações de profissionais de saúde nas práticas sociais e na mudança de hábitos individuais com impactos na coletividade.

Ao observar o mercado como "território de interações, com espaço de escolha e de diálogo entre sujeitos", Baccega (2011, p. 29) constrói relações entre os conceitos de consumo e cidadania, pontuando que ao segundo, deve ser considerado em sua plenitude por meio da consciência, do conhecimento e do exercimento de direitos. A partir dessa interação com os direitos no campo legislativo e como reconhecimento de um sujeito que pertence à estrutura social, é possível compreender como o sujeito ativo pode participar de múltiplos espaços e esboçar sua identidade.

Compreender uma cidadania plena, a partir da estrutura indicada por Baccega (2011), exige ao cidadão/consumidor um papel ativo nas suas decisões e a nas relações que estabelece para a construção e reconstrução de sua identidade. É importante ressaltar também que, em conformidade aos estudos de Hall (1999) e Canclini (1997), Baccega observa que a identidade está em constante modificação e não se forma apenas a partir de uma estrutura familiar ou classe, por exemplo, mas com os elementos mesclados da cultura e diferentes intervenções dos códigos que a tornam variável e provisória.

A esta relação entre consumo, cidadania e as práticas de saúde, pode-se também acrescentar o jornalismo como um mediador do código cultural nos processos de significação 
e construção de argumentos para a ação cidadã. Em suas atuações, o papel comunicativo “confere à informação jornalística sobre saúde, sobre políticas públicas e terapias de saúde, um valor político na esfera da cidadania" (KUCINSKI, 1997, p. 183). Dessa maneira, as dinâmicas sociais no consumo simbólico da saúde são engendradas por diferentes saberes e demarcam lugares de disputa para a organização e resposta da saúde pública.

Observar a dinâmica social que é construída no espaço hospitalar relaciona-se com o sujeito ativo, uma vez que este se entende como alguém com direitos à saúde, e a prática jornalística demonstra que, ao adentrar em espaço clínico, as práticas que envolvem o paciente possuem uma rede mais complexa que o tratamento de um determinado diagnóstico. Dessa forma, o que se inicia como consumo de uma terapêutica em saúde se torna um espaço de interação humana no qual os insumos, sejam medicamentos, atividades e até mesmo a patologia diagnosticada tornam-se condutores de uma relação entre a sociedade e a instituição hospitalar.

A seguir, será realizado um breve histórico do planejamento de comunicação dos dados sobre a Covid-19, o detalhamento do material de divulgação intitulado como "Placar da Vida" e as críticas realizadas pela mídia sobre o formato de comunicação adotado pelo Ministério da Saúde durante a crise sanitária que atravessamos.

\section{A comunicação do governo federal sobre a pandemia}

A partir da declaração de pandemia feita pela Organização Mundial de Saúde (OMS) no dia 11 de março de 2020, o Ministério da Saúde brasileiro, com o então ministro Henrique Mandetta, anunciava as atitudes a serem tomadas junto ao sistema de organização e acompanhamento dos dados sobre casos de Covid-19. Lançada em 26 de março, a plataforma de dados do novo coronavírus começou a ser utilizada como forma de apresentar os dados de casos e óbitos registrados pela Covid-19 com atualização diária, detalhamento de características predominantes e regionalização para identificar espaços de foco da doença. Os dados são atualizados com a colaboração das secretarias municipais e estaduais de saúde. ${ }^{6}$

As atitudes tomadas para o planejamento e estratégias de saúde realizadas pelo ministério, como o isolamento social defendido pelo ex-ministro Henrique Mandetta, tiveram atrito com as propostas e planejamentos de outros ministérios e do presidente da República e, como consequência, a troca de ministros aconteceu em dois momentos até a formação de uma equipe técnica que estivesse de acordo com as propostas do poder executivo federal. Em meio

\footnotetext{
${ }^{6} \mathrm{O}$ método dos cálculos e detalhamento das categorias e funcionamento do painel podem ser verificados na aba “sobre" do portal: https://covid.saude.gov.br/. Acesso em: 19 jun. 2020.
} 
aos conflitos na tomada de decisão do controle da pandemia, os formatos de comunicação dos dados sobre a Covid-19 também tiveram sua execução diversificada e criticada pela imprensa.

As resistências e potencialidades no discurso de saúde promovem em seu consumo diferentes discussões que adentram não somente a construção individual de uma vida saudável como também a função cidadã em seguir práticas que sejam salubres para o coletivo. Nesse processo, é importante compreender o SUS como um espaço onde o poder encontra seu potencial de produção e também seus ritos de verdades, para além do que é controle ou disciplina, tal como nos indica Foucault (2015, p. 189):

Temos que deixar de descrever sempre os efeitos de poder em termos negativos: ele 'exclui', 'reprime'. 'recalca', 'censura', 'abstrai', 'mascara', 'esconde'. Na verdade, o poder produz; ele produz realidade; produz campos de objetos e rituais da verdade. O indivíduo e o conhecimento que dele se pode ter se originam nessa produção.

Para Gomes (2003, p. 100), o "discurso pode ser instrumento de poder e também obstáculo, escora, ponto de resistência". Nesse sentido, podemos ver os lugares de embate nas perspectivas individuais da saúde pública. Isso se confere não somente nas mudanças temporais das ações e insumos consumidos para práticas saudáveis, como também nos imaginários existentes do que vem a ser uma prática saudável, como também no imaginário do que a saúde pública pode fazer. A esses mecanismos de produção, a possibilidade de disciplina controle está em atrito com os pontos de resistência.

Um dos momentos de crítica da imprensa surge com a divulgação dos dados realizada via redes sociais, mais especificamente o Instagram, com o chamado "Placar da Vida", que tinha como base apresentar o número de infectados e os "brasileiros salvos", omitindo o número de óbitos totais e diários tanto em sua arte principal como na descrição da imagem. A proposta de informar os dados dessa maneira surge com a fala do ministro Luiz Eduardo Ramos, da Secretaria de Governo, que em uma entrevista coletiva em abril, tinha reclamado de uma "cobertura maciça de fatos negativos" da imprensa na crise do novo coronavírus (LEMOS, 2020). Nessa publicação, a BBC também reforça que o uso do material recusa a compreensão e comunicação da gravidade da pandemia, minimizando as ações de prevenção e desestimulando práticas individuais seguras na contenção do vírus.

Para que seja possível compreender a função discursiva das comunicações de dados sobre a Covid-19, é importante lembrar que 
[...] uma prática discursiva não é um ato de fala, não é uma ação concreta e individual de pronunciar discursos, mas é todo o conjunto de enunciados que "formam o substrato inteligível para as ações, graças ao seu duplo caráter de judicativo e vericativo". Isso equivale dizer que as práticas discursivas moldam nossas maneiras de constituir o mundo, de compreendê-lo e de falar sobre ele. E, ainda que uma prática discursiva dependa da nossa vontade, essa não é suficiente para gerá-la e fazê-la funcionar (VEIGA-NETO, 2007, p. 93.)

O "Placar da Vida" (2020) ${ }^{7}$ consiste em uma ilustração com a identidade do governo federal vigente, composto pelo título em destaque da comunicação e três informações reportadas na parte inferior, sendo estas o número total de pessoas infectadas, pacientes recuperados sob o título de "brasileiros salvos" e o número de pacientes em recuperação, os dois últimos dados acompanhados pela porcentagem em relação ao número total de casos confirmados, havendo ainda a hashtag "\#NinguémFicaParaTrás". A descrição da imagem postada no Instagram no dia 26 de maio, a mesma data do artigo crítico da BBC ao modelo de divulgação do Ministério da Saúde, reforça as ações administrativas tomadas no dia para conter a pandemia, que omitiram também os canais de acesso aos dados completos registrados no portal do MS.

A publicação diária do "Placar da Vida" ocorreu diariamente entre 27 de abril e 3 de junho, com um intervalo entre os dias 4 e 11 de junho, período marcado por um novo confronto com os dados epidemiológicos, declarações do governo sobre um possível erro no número de registros, atraso na divulgação diária para a imprensa, a retirada do portal de dados completos do ar durante o dia 05 de junho e, até mesmo, a modificação do sistema de contabilidade e de informações a serem divulgadas. Após o dia 12 de junho, as publicações retornaram de forma não regular, com diferentes dados e descrições sobre a Covid-19.

A partir do recorte sobre a divulgação dos dados realizados pelo governo entre os dias 27 de abril e 3 de junho, com ênfase na publicação do dia 26 de maio, é possível fazer algumas conexões com base na discussão de Dunker (2017) sobre a pós-verdade. A versão contemporânea é apresentada pelo autor como uma construção "inflacionada pela subjetividade", na qual "se confunde com os processos sociológicos de individualidade com

\footnotetext{
${ }^{7} \mathrm{O}$ material descrito para análise se refere à publicação do dia 26 de maio de 2020 do "Placar da Vida" pelo Ministério da Saúde no Instagram.
} 
as prerrogativas estéticas do gosto e com a força política das religiões" (DUNKER, 2017, p. 14). Observar os formatos de comunicação e os focos dados por cada vertente a partir da ótica de Dunker demonstra o caráter político e moral das instituições, com maior força na comunicação do Ministério da Saúde e suas implicações de ordem narrativa e icônica para a aceitabilidade e fidelização das populações nas comunicações do governo federal.

Como discurso, Dunker (2017) apresenta a pós-verdade a partir de caracterizações da vida contemporânea, cada vez mais acelerada, icônica e funcionalizada. Dessa forma, analisar o "Placar da Vida" pelas características da pós-verdade, principalmente a partir do que Dunker alerta como a surdez na leitura dos ícones, os destaques para o discurso promovido na divulgação de dados podem ser representados no reforço das mensagens positivas e na omissão dos números de óbitos no material do MS. Apresentando fatos verdadeiros e jogando com o foco de palavras de ordem tais como "brasileiros salvos", "ninguém fica para trás" e "placar da vida", a mensagem transmitida se refere a uma pandemia controlada no território nacional e um argumento de batalha vencida pela saúde pública nacional.

O período de transição entre os representantes do MS e a criação do novo sistema de contagem de pessoas infectadas evidenciou também a intencionalidade discursiva do governo no esquecimento das pautas minoritárias. Em seu caso mais evidente, isso ocorre a partir da supressão dos dados com detalhamento da população negra, ação que, conforme a Associação Brasileira de Saúde Coletiva (ABRASCO $)^{8}$, prejudica o princípio de equidade do SUS, uma vez que a omissão dessas informações aprofunda desigualdades e impede que ações direcionadas sejam realizadas para o controle da propagação do vírus. A esta ausência, é possível construir relações com o que Mbembe (2018) chama de necropolítica, ao questionar as políticas de Estado na organização da vida e na subalternização de determinados grupos para a decisão de quem vive ou morre.

A relação de equidade proposta na legislação do SUS objetiva a diminuição de desigualdades e uma proposta de planejamento e atendimento conforme as necessidades de cada paciente e das regiões em que as práticas de saúde devem ser promovidas. Com a subtração desse detalhamento, o que ocorre é uma desorganização nos insumos de saúde, a recusa do atendimento conforme as necessidades de saúde e ausência de acompanhamento médico aos grupos que podem estar mais expostos a riscos. Retomamos aqui a discussão de Mbembe (2017) sobre os modelos econômicos predatórios que declaram guerra às minorias,

\footnotetext{
${ }^{8}$ A discussão sobre a ausência de dados em relação a população negra feita pela ABRASCO pode ser visualizada no link: https://www.abrasco.org.br/site/noticias/sistemas-de-saude/populacao-negra-e-covid-19desigualdades-sociais-e-raciais-ainda-mais-expostas/46338/.Acesso em: 26 jun. 2020.
} 
colocando-as descartáveis, uma vez que não se encaixam numa hegemonia econômica dos ditos vencedores. A discussão sobre necropolítica e saúde também foi feita pelo Jornal da USP, em uma publicação de 5 de maio de 2020, que reforça também a necessidade de sensibilização e contribuição por parte dos pesquisadores para reflexões interdisciplinares para a determinação social da saúde e da doença (SANTOS, 2020).

Em resumo, a formação discursiva do MS, por meio da publicação de dados do "Placar da Vida", apresenta pelas informações destacadas e omitidas uma mensagem de conquista e superação do vírus, suprimindo os riscos à população e as necessidades de cuidado. As caracterizações de pós-verdade indicadas por Dunker (2017, p. 14) revelam os esforços em propagar uma mensagem que se utiliza de fatos selecionados para produzir um efeito de "verdade que é moralmente potente, mas que não produz transformações éticas relevantes".

Pode-se ainda verificar, na coleta de dados, a ausência de detalhes que são importantes para a criação de políticas de diminuição de desigualdades no tratamento de pacientes infectados e na promoção de saúde. Evidencia também, conforme Mbembe (2018), a necropolítica que afeta minorias a partir da recusa de planejamento com equidade e redução da participação popular, pela ausência de dados que configurem quais as necessidades a serem buscadas pelo coletivo.

A seguir, serão discutidas as possibilidades de participação e emancipação popular a partir dos estudos de Canclini (2020). Discutiremos, ainda, como o caso da Covid-19 se relaciona com a participação cidadã.

\section{O porvir pandêmico: atritos comunicacionais e possibilidades de emancipação}

Ao escrever Ciudadanos reemplazados por algoritmos, Canclini (2020) evidencia algumas possibilidades de emancipação em meio às pautas que envolvem políticas e movimentos sociais. Para compreender os processos de cidadania, o autor destaca o momento de ampliação e acesso a dados que permitem maior autonomia ao papel de cidadão, tais como os casos de corrupção na América Latina e a investigação de crimes na ditadura argentina, mas reforça que esse potencial emancipador confronta-se com "a restauração e o reforço de práticas de dominação, prejuízos e controle de conflitos" (CANCLINI, 2020, p. 150).

Dessa maneira, duas consequências aparecem nas relações entre cidadania e o acesso a dados, sendo a primeira a aparição de líderes com discursos morais e de potência cívica que, 
apoiados por líderes religiosos e pelo mercado neoliberal, empregam nos cidadãos uma ideia de salvação a partir de seus posicionamentos e governança autoritária. A segunda surge pelo papel de intermediação da mídia, que provoca uma judicialização da política, ou seja, um uso crescente de processos e mobilizações a fim de determinados interesses sociais, econômicos e políticos (CANCLINI, 2020).

Tomando as reflexões de Canclini (2020), é possível fazer conexões com o recorte proposto sobre os dados da Covid-19 a partir das perspectivas do governo e da mídia. A possibilidade de verificação dos dados em tempo real por diferentes fontes ampliou a possibilidade de ação social e cidadã pela compreensão do aumento do número de casos por região e pelas medidas de isolamento e prevenção empregadas. Por outro lado, a aceitabilidade de um discurso, seja este do ministério da saúde ou das críticas realizadas pelas empresas de comunicação e associações expostas neste artigo, definiram qual a relevância das atitudes a serem tomadas pela população.

Se pelo lado do governo, o negacionismo da gravidade da pandemia e a omissão do número de óbitos reforçam uma ideia de estabilidade dos planos do poder executivo, a imprensa trata a forma de divulgação dos dados e os posicionamentos do governo como um sério problema de saúde e exemplo de má gestão da crise. Para Kucinski (1997), o ato de evidenciar as problemáticas na divulgação dos dados faz parte de um fazer jornalístico, na forma de socializar discussões que são pertinentes a uma prática cidadã.

A partir desse conflito entre governo e imprensa, as discussões de Canclini (2020) mais uma vez podem ser empregadas como chave de uma possível emancipação, que surge, para o autor, por meio da construção de associações e redes de comunicação que atuem em microescala. Por meio de ações cotidianas que modifiquem os processos nos espaços sociais, Canclini observa o potencial de emancipação e de prática cidadã. É importante ressaltar que, para o autor, não são descartadas as necessidades de reinvenção das instituições, mas as mudanças dos papéis de cidadania surgem com maior potência a partir de ações em microescalas que possibilitam ampliar os ideais de equidade, compreendendo as diferenças individuais e coletivas da sociedade, e assim, desprender-se da "prepotência de quem crê controlar a sociedade, as linguagens e algoritmos" (CANCLINI, 2020. p. 164).

Em relação à pandemia, as ações de cidadania podem ser exemplificadas nas práticas individuais, tal como o uso de máscara por uma pessoa que pode estar contaminada com o vírus Covid-19, uma vez que o uso desse equipamento de proteção individual (EPI) reduz o 
risco de transmissão para outras pessoas que estejam em contato físico, contribuindo para uma proteção coletiva.

Dessa forma, o consumo dos dados de saúde referentes à Covid-19 e a criticidade sobre as formas de divulgação reformulam a participação popular, conforme o ideal definido pela legislação do SUS, se empregadas medidas de proteção individual e ações coletivas de prevenção da doença, tais como a redução de contatos sociais e a higienização de espaços públicos. Compreender a necessidade de atividades de promoção de saúde que surjam de grupos populares é enfrentar e trazer participação pública frente à mensagem de vitória sobre o vírus realizada pelo MS com o destaque de informações que demonstrem práticas ativas do governo no combate à pandemia e a recusa de um discurso que evidencie a gravidade da doença.

\section{Considerações finais}

As comunicações do governo federal e da imprensa sobre os dados de covid-19 demonstram focos diferentes em suas pautas, fazendo com que as mensagens gerem conflitos sobre a necessidade ou não dos cuidados preventivos em relação à pandemia causada pelo vírus Covid-19. A omissão de dados sobre óbitos, a mudança na metodologia de contagem e a exclusão do detalhamento de raça e sexo, por exemplo, no sistema de dados do Ministério da Saúde provocaram críticas e aprofundaram crises nas fundamentações do SUS, principalmente em seu princípio de equidade. Aos atritos discursivos, questões como a necropolítica e a pós-verdade aparecem como possibilidades para visualizar o negacionismo do governo federal frente à gravidade da crise. O papel do jornalismo como instância avaliadora das políticas de saúde e articuladora das ações de saúde propuseram discussões sociais sobre o papel da cidadania por meio da evidenciação das lacunas nas informações e da divulgação de ações preventivas. A partir da discussão de emancipação de Canclini (2020), o consumo desses dados de forma crítica possibilitaria o combate à pandemia a partir de uma frente para ressignificação das práticas cidadãs e do cuidado coletivo de saúde. 
Referências

BACCEGA, Maria Aparecida. Inter-relações comunicação e consumo na trama cultural: o papel do sujeito ativo. In: CARRASCOZA, João Anzanello; ROCHA, Rose de Melo (org.). Consumo midiático e culturas da convergência. São Paulo: Miró, 2011, p. 26-44.

BEER, David. The quirks of digital culture. Bingley, UK: Emerald, 2019.

BRASIL. Conselho Nacional de Secretários de Saúde. Legislação do SUS. Conselho Nacional de Secretários de Saúde. Brasília: CONASS, 2003.

BRASIL. Ministério da Saúde. Secretaria Executiva. Sistema Único de Saúde (SUS): princípios e conquistas. Brasília: Ministério Saúde, 2000.

CANCLINI, Néstor Garcia. Consumidores e cidadãos: conflitos multiculturais da globalização. Rio de Janeiro: UFRJ, 1997.

CANCLINI, Néstor Garcia. Ciudadanos reemplazados por algoritmos. Guadalajara: CALAS, 2020.

DOUGLAS, Mary; ISHERWOOD, Baron. O mundo dos bens: para uma antropologia do consumo. Rio de Janeiro: Editora UFRJ, 2004.

DUNKER, Christian. Subjetividade em tempos de pós-verdade. In: Dunker et al. Ética e pósverdade. Porto Alegre: Dublinenses, 2017, p. 7-37.

FOUCAULT, Michel. Microfísica do poder. Roberto Machado (org.). 3 ed. Rio de Janeiro: Paz e Terra, 2015.

GOMES, Mayra Rodrigues. Palavra de ordem/dispositivo disciplinar. Galáxia, n. 5, v. 1, p. 91-108, 2003.

HALL, Stuart. Identidade cultural na pós-modernidade. 3 ed. Rio: DP\&A, 1999.

KUCINSKI, Bernardo. Jornalismo, saúde e cidadania. Interface (Botucatu), Botucatu, v. 1, n. 1, p. 209-212, 1997. Disponível em: http://dx.doi.org/10.1590/S1414-3283199700020002 1. Acesso em: 23 out. 2020.

LEMOS, Vinícius. 'Placar da vida' do governo estimula negacionismo por omitir realidade trágica da covid-19, dizem cientistas. BBC News Brasil, 26 maio 2020. Disponível em: https://www.bbc.com/portuguese/geral-52765075. Acesso em: 19 jun. 2020.

MBEMBE, Achille. A era do humanismo está terminando. Revista IHU Online, São Leopoldo, RS, 24 jan. 2017. Disponível em: http://www.ihu.unisinos.br/eventos/564255achille-mbembe-a-era-do-humanismo-esta-terminando. Acesso em: 23 jun. 2020. 
MBEMBE, Achille. Necropolítica. São Paulo: N-1, 2018.

PACTO Internacional dos Direitos Econômicos, Sociais e Culturais. Organização das Nações Unidas. 1976. Disponível em: https://brazil.unfpa.org/sites/default/files/pubpdf/pacto_internacional.pdf. Acesso em: 23 jun. 2020.

PLACAR DA VIDA. [Postagem no Instagram]. Ministério da Saúde. 26 maio 2020. Disponível em: https://www.instagram.com/p/CArKOqBgkTD/. Acesso em: 24 jun. 2020.

SANTOS, Gislene Aparecida. Reflexões em tempos de pandemia, necropolítica e genocídios. Jornal da USP, São Paulo, 05 maio 2020. Disponível em: https://jornal.usp.br/artigos/reflexoes-em-tempos-de-pandemia-necropolitica-e-genocidios/. Acesso em: 23 jun. 2020.

VEIGA-NETO, Alfredo. Foucault \& a Educação. 2 ed. Belo Horizonte: Autêntica, 2007.

VENTURA, Miriam; SIMAS, Luciana; PEPE, Vera Lúcia Edais; SCHRAMM, Fermin Roland. Judicialização da saúde, acesso à justiça e a efetividade do direito à saúde. Physis Revista de Saúde Coletiva, Rio de Janeiro, v. 20, n.1, p. 77-100, 2010.

WILleMS, Emilio. Consumo Simbólico. PLURAL, Revista do Programa de Pós-Graduação em Sociologia da USP, São Paulo, v. 20, n. 1, p.141-144, 2013.

Submetido em 01.10.2020

Aprovado em 11.11.2020 